\title{
DISCRETIONARY LOAN LOSS PROVIONS SEBAGAI ALAT DETEKSI MANAJEMEN LABA PADA PERBANKAN KONVENSIONAL DI INDONESIA
}

\author{
Sandra Sukma Embuningtyas \\ sandrasukmae@gmail.com \\ Universitas Nahdatul Ulama
}

\begin{abstract}
This study aims to analyze the effect of profitability, leverage, company size, and environmental performance to environmental disclosure. The population in this study are all manufacturing companies listed on the Indonesia Stock Exchange from 2014 until 2016. The sample in this study were 71 companies for 3 years. The method of analysis used in this study is multiple regression analysis.

The results show that profitability and leverage have no effect on environmental disclosure, while firm size and environmental performance have positive effect on environmental disclosure. Taken together, the variables of profitability, leverage, firm size and environmental performance have significant effect on environmental disclosure.
\end{abstract}

Keywords: Profitability; Leverage; Size; Environmental Performance; Environmental Disclosure 


\section{PENDAHULUAN}

Informasi laba memiliki peranan yang sangat penting bagi para pemakai laporan keuangan. Pentingnya informasi laba karena informasi tersebut kerap kali digunakan sebagai dasar untuk pengambilan keputusan baik itu bagi para investor, kreditor maupun pemerintah. Disamping berbagai manfaat yang ditawarkan, informasi laba juga seringkali memicu para pemangku kepentingan dengan memanfaatkan informasi yang dimiliki untuk memberikan keuntungan yang lebih baik bagi diri pribadi, golongannya maupun perusahaan atau yang lebih dikenal dengan manajemen laba. Scott (2009: 403) mendefinisikan manajemen laba sebagai pilihan kebijakan akuntansi oleh manajer, atau tindakan yang mempengaruhi laba, sehingga mencapai beberapa tujuan laba spesifik yang dilaporkan.

Pada umumnya manajemen laba terjadi karena adanya kesempatan dan keleluasaan yang dimiliki oleh manajemen, dimana pihak manajemen diberikan keleluasaan dalam memilih metode akuntansi yang akan diterapkan perusahaan. Adanya keleluasaan tersebut menyebabkan pihak manajemen dapat menggunakan kesempatan dan kekuasaannya dalam menentukan kebijakan yang digunakan perusahaan untuk mengatur tingkat laba perusahaan yang dapat diterima oleh prinsip-prinsip akuntansi dan aturan standar akuntansi yang berlaku. Munculnya manajemen laba juga dapat dijelaskan dengan agency theory, dimana agency theory menjelaskan bahwa terjadinya manajemen laba dapat dipengaruhi karena adanya konflik kepentingan antara principal (pemilik) dan agent (manajer). Konflik kepentingan tersebut muncul ketika masing-masing pihak baik principal maupun agent berusaha untuk mencapai kemakmuran yang dikehendakinya.

Praktik manajemen laba sendiri telah memunculkan beberapa kasus skandal pelaporan akuntansi yang diantaranya dilakukan oleh Enron, Merck, World Com dan mayoritas perusahaan lain di Amerika Serikat. Di Indonesia adanya praktik manajemen laba juga ditemukan pada beberapa perusahaan publik diantaranya yaitu pada PT. Lippo Tbk dan PT. Kimia Farma Tbk. Fenomena mengenai adanya manajemen laba juga telah ditunjukkan dan didukung oleh beberapa bukti empiris diantaranya yaitu De Angelo (1988), Holthausen dan Sloan (1995), Gu dan Lee (1999), Barth et al., (2005), Burgstahler dan Dichev, (1997), dan Zhou et al., (2009). Lebih lanjut Shen dan Chih (2005) memperkuat bukti adanya fenomena manajemen laba dalam kegiatan bisnis. Shen dan Chih (2005) mengatakan bahwa praktik manajemen laba juga ditemukan pada industri perbankan di seluruh dunia. Beberapa literatur menunjukkan bahwa manajer bank termotivasi untuk meminimalkan volatilitas laba dari waktu ke waktu.

Pada industri perbankan, salah satu bentuk praktik manajemen laba yang dapat dilakukan yaitu income smoothing. Income smoothing (perataan laba) merupakan suatu tindakan atau cara yang dilakukan oleh manajemen untuk mengurangi fluktuasi laba dengan menggunakan metode akuntansi tertentu. Othman dan Mersni (2014) mengatakan bahwa manajer pada industri perbankan memiliki insentif untuk melakukan income smoothing melalui LLP. Loan Loss Provision dinilai sebagai akrual 
yang paling penting pada sektor perbankan. Loan Loss Provision sendiri di Indonesia lebih dikenal dengan Penyisihan Penghapusan Aktiva Produktif (PPAP) yang kemudian istilah tersebut diganti menjadi Cadangan Kerugian Penurunan Nilai (CKPN) setelah adanya revisi PSAK 55 tahun 2006.

Pada industri perbankan, penelitian yang menyelidiki praktik manajemen laba pada perbankan konvensional telah banyak dilakukan, namun hasil temuan para peneliti mengungkapkan beberapa bukti yang beragam. Beberapa penelitian yang dilakukan dalam menguji prakti manajemen laba pada perbankan konvensional kebanyakan menggunakan LLP sebagai proksi untuk mendeteksi adanya manajemen laba. Pada penelitian ini lebih memilih menggunakan Discretionary Loan Loss Provisions (DLLP) dibandingkan dengan menggunakan Loan Loss Provisions (LLP) sebagai proksi untuk mengukur manajemen laba. Hal tersebut mengingat di Indonesia, penelitian yang menggunakan DLLP sebagai proksi untuk mengukur manajemen laba masih relatif sedikit. Selain itu, menurut Shawtari et al., (2015) menggunakan DLLP sebagai proksi untuk kualitas laba dapat memberikan penilaian yang lebih baik untuk diskresioner akrual yang tergantung pada manajer bukan pada aktivitasnya.

Pada penelitian ini menggunakan variabel Earning Before Tax and Provisions (EBTP) yang merupakan proksi dari profitabilitas dimana variabel EBTP sering digunakan dalam penelitian-penelitian sebelumnya sebagai proksi untuk praktik manajemen laba
(Taktak et al., 2010). Begitu pula variabel Capital Adequacy Ratio (CAR) yang merupakan proksi dari rasio permodalan serta variabel Loan to Deposit Ratio yang merupakan proksi dari likuiditas yang diduga sebagai alasan untuk dilakukannya praktik manajemen laba.

\section{KERANGKA TEORITIS DAN HIPOTESIS \\ Agency Theory}

Jensen dan Meckling (1976) mendefinisikan agency theory sebagai suatu teori yang menjelaskan hubungan kontraktual di mana satu orang atau lebih (principal) melibatkan orang lain (agent) untuk melakukan beberapa layanan atas nama mereka dengan memberikan pendelegasian sebagian wewenang pengambilan keputusan kepada agent tersebut. Pada hakekatnya hubungan antara principal dan agent sulit tercipta karena adanya kepentingan yang saling bertentangan antara satu dengan yang lainnya. Permasalahan yang muncul adalah ketika masing-masing pihak bertindak dengan tujuan atau kepentingan masing-masing, principal hanya tertarik pada segala sesuatu yang berkaitan dengan hasil yang maksimal dari usaha yang dikelola, sedangkan agent menginginkan hasil yang maksimal atas usaha yang dilakukan sehingga dia memperoleh gaji, bonus serta insentif yang memadai dan maksimal atas kinerja yang dilakukan (Anggraeni, 2011; dalam Fauzan, 2016).

Implikasi agency theory pada penelitan ini adalah agency theory dipertimbangkan dapat menjelaskan bagaimana bank konvensional sebagai agent tidak terlepas dari praktik manajemen laba. Bank konvensional berusaha untuk menunjukkan kepada 
publik dan stakeholder bahwa kedua bank tersebut memiliki kinerja yang baik dan telah melaksanakan segala tugas dan fungsinya dengan benar dan tepat, sehingga principal akan memberikan penilaian yang baik bagi bank konvensional.

\section{Manajemen Laba}

Healy dan Wahlen (1999) mendefinisikan manajemen laba sebagai upaya manajemen dalam mengubah laporan-laporan keuangan untuk menyesatkan beberapa stakeholder mengenai kinerja keuangan utama perusahaan atau untuk mempengaruhi hasil kontrak yang tergantung pada angka-angka laporan akuntansi. Sementara itu Mulford dan Comiskey (2002: 59) menjelaskan bahwa manajemen laba adalah bentuk khusus dari financial numbers game (permainan angka-angka keuangan), di mana fleksibilitas GAAP digunakan untuk mengarahkan laba menuju sasaran yang telah ditentukan.

Healy dan Wahlen menjelaskan bahwa manajemen laba terjadi ketika para manajer menggunakan pertimbangan mereka dalam menyusun laporan keuangan dan struktur akuntansi untuk mengubah laporan keuangan (Belkaoui, 2004: 75). Tujuannya yaitu untuk memanipulasi besarnya laba yang akan dilaporkan kepada pemangku kepentingan (stakeholder) dan untuk mempengaruhi hasil perjanjian yang bergantung pada angka-angka akuntansi yang dilaporkan. Scott (2009: 405) menyatakan bahwa terdapat empat pola yang dilakukan manajemen untuk melakukan manajemen laba diantaranya yaitu: (1) taking a bath, (2) income minimization, (3) income maximization dan (4) income smoothing.

Pengaruh Profitabilitas terhadap Discretionary Loan Loss Provisions

Profitabilitas merupakan indikator kinerja manajemen dalam mengelola kekayaan perusahaan yang ditunjukkan oleh laba yang dihasilkan perusahaan (Sudarmaji dan Sularto, 2007; dalam Guna dan Herawaty, 2010). Guna dan Herawaty (2010) menjelaskan bahwa laba yang dihasilkan oleh perusahaan selama tahun berjalan dapat menjadi indikator terjadinya manajemen laba dalam suatu perusahaan. Earning Before Tax and Provisions (EBTP) atau laba bersih sebelum dikurangi pajak dan provisi merupakan variabel yang menunjukkan kemampuan suatu bank dalam menghasilkan laba dari aktivitas operasionalnya. Menurut Tobing dan Nur (2009, dalam; Sariati dan Marlinah, 2015) ketika bank memiliki kinerja yang baik yaitu memiliki keuntungan/laba yang cukup tinggi pada periode berjalan dan memprediksi kinerja yang tidak baik di waktu yang akan datang, manajer bank cenderung akan menyimpan atau mengurangi laba periode berjalan untuk digunakan di waktu yang akan datang dengan cara mengurangi laba melalui peningkatan LLP. Sedangkan ketika bank memiliki kinerja yang tidak baik di periode berjalan dan memprediksi kinerja yang baik di waktu yang akan datang, bank akan meningkatkan laba periode berjalan dengan cara meminjam laba masa depan melalui penurunan LLP.

Berdasarkan penjelasan diatas, maka dirumuskan hipotesis sebagai berikut:

\section{H1: Profitabilitas yang diukur menggunakan proksi EBTP (Earnings Before Taxes and}


Provisions) berpengaruh positif terhadap Discretionary Loan Loss Provisions pada bank konvensional

\section{Pengaruh Permodalan terhadap Discretionary Loan Loss Provision}

Bagi industri perbankan modal merupakan askpek yang sangat penting. Oleh karenanya industri perbankan memiliki regulasi yang lebih ketat dibandingkan dengan industri lainnya yaitu kaitannya dalam mengatur permodalan bagi suatu bank. Setiawati dan Na'im (2001), Rahmawati (2006), dan Rahmawati dan Baridwan (2006) menjelaskan bahwa, agar dapat memenuhi ketentuan rasio kecukupan modal minimum yang ditetapkan BI, perbankan di Indonesia melakukan praktik manajemen laba.

Pada penelitian yang dilakukan oleh Ahmed et al., (1999) dan Kim dan Kross (1993) menunjukkan bahwa bankbank dengan rasio modal yang rendah cenderung akan menggunakan kebijakan mereka dan melaporkan Discretionary Loan Loss Provisions yang lebih rendah dengan tujuan untuk melaporkan modal dan laba yang lebih tinggi. Lebih lanjut Cornett et al., (2009) menjelaskan bahwa karena pada sektor perbankan modal diatur sangat ketat, sehingga ketika bank mengalami tingkat modal yang rendah, manajer memiliki insentif untuk menghindari melaporkan kredit macet dan untuk mengakui keuntungan lebih atas sekuritas dalam rangka untuk menopang tingkat modal. Hasil penelitian Shawtari et al., (2015) menunjukkan adanya hubungan negatif antara rasio CAR dengan DLLP.
Berdasarkan penjelasan diatas, maka dirumuskan hipotesis sebagai berikut:

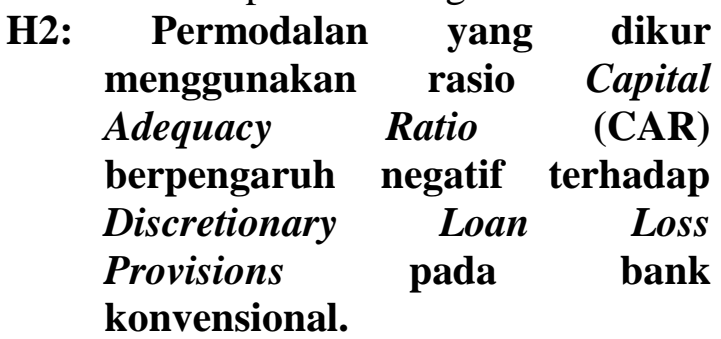

\section{Pengaruh Likuiditas terhadap Discretionary Loan Loss Provisions}

Manajemen likuiditas adalah hal yang penting dalam operasional bank, hal tersebut karena sebagian besar dana yang dikelola oleh bank bersumber dari pihak ketiga atau dari masyarakat yang dititipkan dalam beberapa bentuk seperti tabunggan, deposito, rekening giro, dan simpanan lainya yang harus dibayar pada saat sudah jatuh tempo (Dewi, 2010). Pada faktanya, untuk menarik dana eksternal, bank melaporkan DLLP yang rendah untuk mengurangi perceived risk dan meningkatkan pendapatan yang dilaporkan. Jika rasio LDR tinggi, menunjukkan bahwa total pembiayaan lebih besar dari deposito dan oleh karena itu bank perlu untuk menarik lebih banyak simpanan dari nasabah, untuk itu manajer bank memiliki insentif untuk melaporkan DLLP yang rendah. Hasil penelitian Othman dan Mersni (2014) menunjukkan adanya hubungan yang negatif antara LDR dan DLLP. Othman dan Mersni (2014) mengatakan bahwa kebutuhan pembiayaan eksternal adalah faktor utama yang mempengaruhi estimasi LLP oleh manajer.

Berdasarkan penjelasan diatas, maka dirumuskan hipotesis sebagai berikut: 


\section{H3: Likuiditas yang diukur menggunakan rasio loan to deposit (LDR) berpengaruh negatif terhadap discretionary loan loss provisions pada bank konvensional}

\section{METODOLOGI}

Jenis Penelitian

Jenis penelitian ini merupakan penelitian kuantitatif yaitu penelitian yang menekankan pada pengujian teoriteori melalui pengukuran variabelvariabel penelitian dengan angka-angka dan melakukan analisis data dengan prosedur statistik.

\section{Jenis dan Sumber data}

Jenis data yang diteliti dalam penelitian ini adalah data sekunder yang bersumber dari annual report, laporan keuangan dan laporan keuangan triwulanan bank umum syariah dan bank konvensional.

\section{Populasi dan Sampel Penelitian}

Populasi dalam penelitian ini adalah bank konvensional (bank umum) di Indonesia, dimana penarikan sampel dilakukan dengan menggunakan metode purposive sampling yaitu sampel yang dipilih peneliti berdasarkan penilaian dan pertimbangan terhadap beberapa karakteristik anggota sampel yang disesuaikan dengan tujuan penelitian.

Sampel yang digunakan dalam penelitian ini adalah:

Tabel 1

Sampel Penelitian

\begin{tabular}{clcc}
\hline Bank & \multicolumn{1}{c}{ Kriteria } & Jumlah & Total \\
\hline & $\begin{array}{l}\text { Bank umum konvensional yang terdaftar di } \\
\text { BI dan telah go public periode 2011-2015. }\end{array}$ & 32 & \\
& $\begin{array}{l}\text { Bank umum konvensional yang mengalami } \\
\text { rugi selama periode pengamatan dari tahun }\end{array}$ & & \\
BKN & (5) & \multirow{2}{*}{20} \\
& $\begin{array}{l}\text { 2011-2015. } \\
\text { Data bank umum konvensional tidak } \\
\text { lengkap dan tidak ditemukan. }\end{array}$ & (4) & \\
Data outlier & (3) & \\
\hline Total Seluruh Sampel Penelitian & & $\mathbf{3 5}$ \\
\hline
\end{tabular}

Sumber : Data sekunder yang telah diolah

Operasionalisasi Variabel Penelitian Variabel Dependen

Discretionary Loan Loss Provisions (DLLP).

DLLP merupakan keleluasaan yang dimiliki oleh pihak manajemen bank dalam mengatur atau mengevaluasi LLP. Mengikuti literatur sebelumnya, untuk memeriksa penggunaan diskresi oleh manajer bank konvensional di Indonesia, penelitian ini menggunakan pendekatan dua tahap. Pada tahap pertama, menggunakan akrual khusus untuk mengukur manajemen laba buatan, yang secara lebih khusus menggunakan akrual utama di sektor perbankan yaitu LLP. Proksi ini terbagi menjadi dua komponen yaitu: discretionary dan non- 
discretionary. Dimana modelnya adalah sebagai berikut:

LLP $=$ Non-discretionary LLP + Discretionary LLP

Sama halnya dengan

Kanagaretnam et al., (2004) dan Kwak et al., (2009), komponen NDLLP diestimasi menggunakan serangkain variabel yang informatif yaitu NPL awal, perubahan NPL dan perubahan total kredit/pembiayaan. NDLLP diestimasi menggunakan persamaan berikut

$$
\mathrm{LLP}_{\mathrm{it}}=\beta_{0}+\beta_{1} \mathrm{NPL}_{\mathrm{it}-1}+\beta_{2} \Delta \mathrm{NPL}_{\mathrm{it}}+\beta_{3} \Delta \mathrm{TL}_{\mathrm{it}}+\epsilon_{\mathrm{it}}
$$

Di mana:

LLP $_{\text {it }} \quad=$ Total LLP pada bank i pada tahun $\mathrm{t}$

NPLit $-1=$ NPL awal pada bank i pada tahun $\mathrm{t}$

$\Delta \mathrm{NPL}_{\mathrm{it}}=$ Perubahan nilai NPL pada bank i pada tahun $\mathrm{t}$

$\Delta \mathrm{TL}_{\mathrm{it}} \quad=$ Perubahan nilai total pembiayaan pada bank $\mathrm{i}$ pada tahun $\mathrm{t}$

DLLP terdiri dari prediksi eror Tahapan selanjutnya mengevaluasi LLP yang diestimasi melalui residual komponen non-discretionary LLP yang diperoleh dari persamaan (1). (NDLLP):

$\mathrm{NDLLP}_{i t}=\hat{\beta_{0}}+\beta_{1} \mathrm{NPL}_{\mathrm{it}-1}+\hat{\beta}_{2} \Delta \mathrm{NPL}_{\mathrm{it}}+\beta_{3} \Delta \mathrm{TL}_{\mathrm{it}}$

Pada tahap terahir, diperoleh komponen DLLP dengan menghitung selisih antara total LLP dan estimasi NDLLP. Persamaan dasar estimasi menjadi:

$\operatorname{DLLP}_{\text {it }}=\operatorname{LLP}_{\text {it }}-\mathrm{NDLLP}_{\text {it }}$

\section{Variabel Independen}

1) Profitabilitas (Earning Before Taxes and Provisions)

Earning Before Tax and Provisions (EBTP) atau laba bersih sebelum dikurangi pajak dan provisi merupakan variabel yang menunjukkan kemampuan suatu bank dalam menghasilkan laba dari aktivitas operasionalnya. EBTP dapat dihitung dengan rumus sebagai berikut:

$$
\text { EBTP }=\frac{\text { Laba sebelum pajak }+ \text { beban (pendapatan)PPAP }}{\text { Total Aset }}
$$

2) Permodalan Adequacy Ratio)

Capital Adequacy Ratio (CAR) merupakan rasio permodalan yang menunjukkan kemampuan suatu bank

(Capital dalam menyediakan dana untuk keperluan pengembangan usaha dan menampung risiko kerugian dana yang diakibatkan oleh kegiatan operasi bank. CAR dapat dihitung dengan rumus sebagai berikut: 


\section{Error! Reference source not found. $\times 100 \%$}

3) Likuiditas (Loan to Deposit membayar kembali penarikan dana yang Ratio)

Loan to Deposit Ratio (LDR)

merupakan rasio yang menyatakan seberapa jauh kemampuan bank dalam

dilakukan deposan dengan mengendalikan kredit yang diberikan sebagai sumber likuiditasnya. LDR dapat dihitung dengan rumus sebagai berikut:

Error! Reference source not found. $\times 100 \%$ 


\title{
Variabel Kontrol \\ Ukuran Bank (size)
}

\author{
Ukuran bank mencerminkan \\ besarnya total aset yang dimiliki oleh \\ perusahaan. Othman dan Mersni (2014) \\ menyebutkan bahwa ukuran bank sering
}

kali dianggap sebagai faktor penting yang dapat mempengaruhi perilaku manajemen laba.

Berdasarkan penelitian sebelumnya SIZE dihitung dengan rumus sebagai berikut:

$S I Z E=$ Logaritma Natural (Total Asset $)$ 


\section{Model Regresi Data Panel}

Model persamaan yang digunakan adalah:

$$
Y_{i, t}=\beta_{0}+\beta_{1} X_{1 i, t}+\beta_{2} X_{2 i, t}+\beta_{3} X_{3 i, t}+\beta_{4} X_{4 i, t}+e_{i t}
$$

Keterangan:

$$
\begin{array}{ll}
\mathrm{Y} & =\text { Discretionary Loan Loss Provisions } \\
\mathrm{B}_{0} & =\text { Konstanta } \\
\beta_{1,2,3,4} & =\text { Koefisien variabel } \mathrm{X}_{1}, \mathrm{X}_{2}, \mathrm{X}_{3}, \mathrm{X}_{4} \\
X_{1} & =\text { Variabel profitabilitas (earning before tax and provision) } \\
X_{2} & =\text { Variabel permodalan (capital adequacy ratio) } \\
X_{3} & =\text { Variabel likuiditas (loan to deposit ratio) } \\
X_{4} & =\text { Variabel ukuran bank (size) } \\
\mathrm{e} & =\text { error }
\end{array}
$$

HASIL ANALISIS DAN PEMBAHASAN Statistik Deskriptif

Tabel 2

Statistik Deskriptif Bank Konvensional

\begin{tabular}{lcccccc}
\hline & N & Mean & Median & Maximum & Minimum & $\begin{array}{c}\text { Std. } \\
\text { Deviation }\end{array}$ \\
\hline DLLP & 100 & 0,042 & 0,025 & 4,521 & $-4,149$ & 1,780 \\
EBTP & 100 & 0,023 & 0,019 & 0,055 & 0,002 & 0,014 \\
LN_CAR & 100 & 2,911 & 2,831 & 4,472 & 2,094 & 0,372 \\
LN_LDR & 100 & 4,362 & 4,416 & 4,628 & 2,614 & 0,238 \\
LN_SIZE & 100 & 30,547 & 29,921 & 34,445 & 26,534 & 1,868 \\
\hline
\end{tabular}

Sumber: output eviews

\section{Pengaruh Profitabilitas terhadap Discretionary Loan Loss Provisions}

Berdasarkan hasil analisis dan pengujian hipotesis yang telah dilakukan, menunjukkan bahwa variabel EBTP menunjukkan adanya pengaruh yang negatif dan signifikan. Signifikannya variabel EBTP terhadap DLLP menunjukkan bahwa EBTP merupakan faktor penting yang dapat mempengaruhi penggunaan kebijakan oleh manajer ketika melaporkan LLP. Dengan demikian, agar perusahaan terlihat memiliki kinerja yang baik perusahaan berusaha menunjukkan laba yang cukup tinggi, dengan melakukan diskresi pada LLP dengan tingkat yang rendah. Hasil temuan penelitian ini sesuai dengan agency theory yang dikemukakan oleh Jensen dan Meckling (1976). Adanya pendelegasian wewenang yang dilimpahkan oleh pihak prinsipal kepada pihak agent menyebabkan agent mengetahui lebih banyak informasi mengenai perusahaan dibandingkan 
dengan principal. Informasi yang dimiliki tersebut digunakan salah satunya dengan tujuan untuk menunjukkan kepada publik dan stakeholder bahwa pihak manajemen memiliki kinerja yang baik dan telah

melaksanakan segala tugas dan fungsinya dengan benar dan tepat. Hasil temuan ini mendukung hasil temuan Kwak et al., (2009) yang menunjukkan adanya pengaruh negatif yang signifikan antara variabel EBTP dengan variabel DLLP.

\section{Pengaruh Permodalan (CAR) terhadap DLLP}

Berdasarkan hasil analisis dan pengujian hipotesis yang telah dilakukan, menunjukkan bahwa variabel CAR berpengaruh signifikan terhadap variabel DLLP. Variabel CAR memiliki pengaruh yang signifikan terhadap DLLP kemungkinan dikarenakan adanya ketentuaan tingkat modal yang harus dimiliki oleh industri perbankan. Pentingnya modal pada industri perbankan menyebabkan regulator lebih ketat dalam memantau tingkat modal yang dimiliki perusahaan. Menurut ketentuan Bank for International Settlements, bank yang termasuk dinyatakan sebagai bank sehat harus memiliki CAR minimal sebesar $8 \%$ permodalan terhadap aktiva berisiko (Muhammad, 2005 dalam Dewi, 2010). Oleh karena itu, manajer pada bank konvensional berupaya dapat memenuhi tingkat kecukupa modal yang ditetapkan oleh pemerintah dengan cara mengelola tingkat LLP perusahaan. Hal ini sejalan dengan stewardship theory yang diperkenalkan oleh Donaldson dan Davis pada tahun 1991 .

\section{Pengaruh Likuiditas (LDR) terhadap DLLP}

Berdasarkan hasil pengujian hipotesis serta analisis data yang telah dilakukan, menunjukkan bahwa variabel LDR memiliki pengaruh positif namun signifikan terhadap DLLP. Hasil penelitian ini mendukung signalling theory yang dikemukakan oleh Ross (1979) yang menjelaskan mengapa suatu perusahaan memiliki dorongan untuk memberikan informasi laporan keuangan kepada pihak eksternal. Perusahaan memiliki dorongan untuk memberikan informasi adalah agar dapat memberikan sinyal kepada pihak luar, salah satunya yaitu berupa informasi kinerja keuangan yang akan direspon oleh berbagai pihak eksternal yang berkepentingan terhadap perusahaan tersebut (Rokhlinasari, 2014)

\section{Pengaruh ukuran perusahaan (size) terhadap DLLP}

Tabel 3

Hasil Pengujian dengan Variabel Kontrol

\begin{tabular}{lc}
\hline \multicolumn{1}{c}{ Variabel } & $P$-Value \\
\hline Dependen: & \\
DLLP & 0,0029 \\
Independen: & \\
EBTP & 0,0037 \\
LN_CAR & 0,0545 \\
LN_LDR & 0,0496 \\
LN_SIZE & 0,0195 \\
\hline
\end{tabular}


Tabel 4

Hasil Pengujian tanpa variabel kontrol

\begin{tabular}{lc}
\hline \multicolumn{1}{c}{ Variabel } & $P$-Value \\
\hline Dependen: & \\
DLLP & 0,0048 \\
Independen: & \\
EBTP & 0,0023 \\
LN_CAR & 0,1753 \\
LN_LDR & 0,0038
\end{tabular}

Berdasarkan tabel 3 dan 4, menunjukkan bahwa pengujian pada bank konvensional dengan memasukkan variabel size diperoleh hasil yang lebih baik, yaitu ditunjukkan dengan banyaknya variabel lainnya yang memenuhi $\alpha$ pada pengujian dengan menggunakan variabel size. Sedangkan apabila tanpa menggunakan variabel size jumlah variabel lainnya yang memenuhi $\alpha$ jumlahnya menurun. Selain itu, berdasarkan hasil pengujian dengan menggunakan variabel size diperoleh hasil yang menunjukkan bahwa variabel size berpengaruh positif terhadap DLLP. Dengan demikian, berpengaruh positifnya variabel size terhadap DLLP pada bank konvensional kemungkinan karena ukuran bank mencerminkan besarnya total aset yang dimiliki oleh perusahaan. Hasil penelitian ini mendukung hasil penelitian Zoubi dan Al-Hhazali (2007), Taktak et al., (2010) dan Shawtari et al., (2015).

\section{SIMPULAN}

Berdasarkan hasil pengujian hipotesis serta analisis hasil penelitian dan pembahasan, hasil penelitian ini menunjukkan bahwa bahwa keempat variabel independen yang dibangun yaitu profitabilitas, permodalan, likuiditas, 26 serta variabel kontrol size berpengaruh terhadap DLLP pada bank konvensional. Dengan demikian dapat disimpulkan bahwa, praktik manajemen laba yang dilakukan oleh bank konvensional dilakukan karena adanya tujuan opportunistic motive, memenuhi peraturan regulasi serta untuk memberikan signal positive kepada stakeholder. Selanjutnya, variabel size dimana variabel tersebut merupakan variabel kontrol menunjukkan adanya pengaruh yang signifikan pada bank umum konvensional.

\section{SARAN}

Saran yang dapat diberikan oleh peneliti dari hasil penelitian yang telah dilakukan antara lain adalah bagi para peneliti selanjutnya disarankan menambahkan faktor-faktor lainnya baik variabel keuangan maupun non keuangan seperti besarnya pajak dan besarnya hutang yang ditanggung oleh perusahaan. Selain itu, berdasarkan hasil penelitian yang telah dilakukan menunjukkan bahwa variabel size yang merupakan variabel kontrol yang digunakan dalam penelitian ini menunjukkan adanya pengaruh terhadap keputusan perusahaan dalam memanfaatkan DLLP untuk praktik manajemen laba. Dengan demikian, penelitian selanjutnya diharapkan untuk menggunakan size sebagai variabel independen. Lebih lanjut, bagi para peneliti selanjutnya diharapkan dapat menambah objek penelitian pada beberapa negara yang berbeda serta memperpanjang periode pengamatan agar dapat diperoleh hasil yang lebih akurat. 


\section{DAFTAR PUSTAKA}

Ahmad, N; Santoso, A. L; Murni, S dan Nugrahaningsih. 2015. Apakah Manajemen Laba Pada Bank Syariah Lebih Rendah Dari Bank Konvensional? Proceeding Konferensi Regional Akuntansi II Malang.

Ahmed, A. S; Takeda, C. dan Thomas, S. 1998. Bank Loan Loss Provisions: A Reexamination of Capital Management, Earnings Management and Signaling Effects. Journal of Accounting and Economics, Vol. 28, hal. 1-25.

Barth, M. E; W. R. Landsman dan M. Lang. 2005. International Accounting Standard and Accounting Quality. Working paper, Stanford University and University of North Carolina.

Beatty, A; Chamberlain, S dan Magliolo, J. 1995. Managing Financial Reports of Commercial Banks: The Influence of Taxes, Regulatory Capital, and Earnings. Journal of Accounting Research, Vol. 33, hal. 231-262.

Burgstahler, D dan I. Dichev. 1997. Earnings Management to Avoid Earnings Decreases and Losses. Journal of Accounting and Economics, hal. 99-126.

Cornett, M.M; McNutt, J.J dan Tehranian, H. 2009. Corporate Governance and Earnings Management at Large US Bank Holding Companies. Journal of Corporate Finance, Vol. 15, hal. 412-430.
De Angelo, L. E. 1986. Accounting Number as Market Valuation Substitutes: A Study of Management Buyout of Public Stockholders. The Accounting Review 41: 400-420.

Dewi, R. I. 2010. Faktor-faktor yang Mempengaruhi Profitabilitas Bank Syariah di Indonesia, Skripsi FEB, Universitas

Diponegoro, Semarang.

Fauzan. 2016. Efek Mediasi Informasi Asimetris dan Moderasi Locus of Control pada Pengaruh Partisipasi Anggaran dan Penekan Anggaran, terhadap Budgetary Slack, Tesis $F E B$, Universitas Jenderal Soedirman, Purwokerto.

Ghozali, I. 2011. Aplikasi Analisis Multivariat dengan Program IBM SPSS 19. Edisi 5. Semarang: Badan Penerbit Universitas Diponegoro.

Gujarati, D. N. 2003. Basic Econometric. Mc Graw Hill. Fourth Edition.

Gujarati, D. N dan Porter, Dawn. C. 2012. Dasar-dasar Ekonometrika. Edisi 5. Terjemahan. Jakarta: Salemba Empat.

$\mathrm{Gu}, \mathrm{Z}$ dan Lee. C. J. 1999. How Widespread is Earnings Management? The Intra-Year Timing Evidence. Working Paper, Carnegie Mellon University.

Guna, W. I dan Herawaty, A. 2010. Pengaruh Mekanisme Good Corporate Governance, Independensi Audior, Kualitas Audit dan Faktor Lainnya 
terhadap Manajemen Laba. Jurnal Bisnis dan Akuntansi, Vol. 12, No. 1, hal. 53-68.

Healy, P. dan Wahlen, J. 1999. A review of the earnings management literature and its implications for standard setting. Accounting Horizons, hal, 365-383.

Holthausen, R. D. L dan Sloan, R. 1995. Annual bonus schemes and the manipulation of earnings. Journal of Accounting and Economics, hal: 73-109.

Kanagaretnam, K; Lobo, G. J. dan Mathieu, R. 2004. Earnings management to reduce earnings variability: evidence from bank loan loss provisions. Review of Accounting and Finance, Vol. 3, hal. 128-148.

Kim, M. and Kross, W. 1998. The impact of the 1989 change in bank capital standards on loan loss provisions and loan write-offs. Journal of Accounting and Economics, Vol. 25, No. 1, hal. 69-100.

Kwak, W; Lee, Y.H. dan Eldidge, S. 2009. Earnings management by Japanese bank managers: using discretionary loan loss provisions. Review of Pacific Basin Financial Markets and Policies, Vol. 12, No. 1, hal. 1-26.

Lobo, G.J. dan Yang, D.H. 2001. Bank managers' heterogeneous decisions on discretionary loan loss provisions. Review of
Quantitative Finance and Accounting, Vol. 16, hal. 223-250.

Mulford, C and Eugene Comiskey. 2002. The Financial Numbers Game Detecting Creative Accounting Theory. New York: John Wiley and Sons, Inc.

Othman, H. B dan Mersni, H. 2014. The Use of Discretionary Loan Loss Provisions by Islamic Banks and Conventional Banks in The Middle East region A comparative study. Studies in Economics and Finance, Vol. 31, No. 1, hal. 106128.

Rahmawati. 2006. Model Penelitian Manajemen Laba pada Industri Perbankan Publik di Indonesia dan Pengaruhnya Terhadap Kinerja Perbankan. Artikel yang Dipresentasikan pada Seminar Bulanan Jurusan Akuntansi FEUNS tanggal 27 Mei 2006.

, 2006. Pengaruh Asimetri Informasi pada Hubungan antaraRegulasi Perbankan dan Manajemen Laba serta Dampaknya pada Kinerja Saham. Jurnal Akuntansi dan Bisnis. Vol. 6, No.1, hal: 41-54.

Rokhlinasari, S. 2014. Perbankan Syariah dan Manajemen Laba. Jurnal Al Amwal, Vol. 6, No. 1.

Sariati, P dan Marlinah, A. 2015. Faktorfaktor yang Mempengaruhi PPAP pada Bank Syariah dan Bank Konvensional di Indonesia. Jurnal Bisnis dan Akuntansi, Vol. 17, No. 1, hal. 46-55. 
Schipper, Katherine. 1989. Commentary on Earning Management. Journal of Accounting Horizons. Vol. 3, No. 4, hal. 91-102.

Scott, W. R. 2009. Financial Accounting Theory. Edisi Kelima. Prentice Hall.

Setiawati, L dan Ainun Na'im. 2001. Bank Health Evaluation by Bank Indonesia and Earnings Management in Banking Industry. Gadjah Mada International Journal of Business, Vol. 3, No. 2, hal.159-176.

Shawtari, F. A; Saiti, B; Razak, S. H. A dan Arif, M. 2015. The Impact of Efficiency on Discretionar loans/finance loss provisio: A Comparative Study of Islamic and Conventional Banks. Bursa Istanbul Review, Vol. 15, No. 4, hal. 272-282.

Shen, C. dan Chih. H. 2005. Investor Protection, Prospect Theory, and Earnings Management: An international comparison of the banking industry. Journal of Banking and Finance. Vol. 29, No. 10, hal. 2675-2697.
Taktak, B. N; Zouari, S. B. S dan Boudriga, A. 2010. Do Islamic banks use loan loss provisions to smooth their results?. Journal of Islamic Accounting and Business Research, Vol. 1, No. 2, hal. 114127.

Wibowo, S. 2015. Analisis Perbandingan Kinerja Keuangan Perbankan Syariah dengan Metode CAMEL di ASEAN. Journal of Research in Economics and Management, Vol. 15, No. 1, hal. 136-153.

Widarjono, A. 2016. Ekonometrika Pengantar dan Aplikasinya Disertasi Panduan Eviews Edisi Keempat. UPP STIM YKPN: Yogyakarta.

Xie, B; Davidson III, Wallace N, dan DaDalt, Peter J. 2003. Higher Market Valuation of Companies with Small Board of Directors. Journal of Financial Economics, hal. 185-211.

Zhou, H., K; Koong dan Y. Xiong. 2007. Accounting Standards and Quality of Earnings Information: Evidence form an Emerging Economy. International Journal of Electronic Finance, hal. 355 - 372 